\title{
The Black-Scholes Formulation of Option Pricing with Credit Risk
}

\author{
Zhaohai WANG \\ Department of Mathematics,Ankang College,Ankang,Shanxi,725000,china \\ akwzh@163.com
}

\begin{abstract}
Black-Scholes Formulation is based on the hypothesis that market is complete and perfect, but the reality of financial markets and trading environment don't like that, which affected the practicality and authenticity of the pricing formula. In an imperfect market, hedging strategies and option pricing methods should make another adjustment. Price with credit risk is an adjustment to perfect market. In fact most of OTC options contain credit risk.
\end{abstract}

Keywords: Option; Credit risk; Martingale; Risk neutrality

\section{Introduction}

The revolution on derivative securities, both in the stock exchange markets and in academic communities, began in the early 1970's.In 1973, the Chicago Board of Options Exchange started the trading of options in exchanges, although options had been regularly traded by financial institutions in the over-the-counter markets previously. Black and Schles ${ }^{[1]}$ (1973)and Merton $^{[2]}$ (1973) published their seminal papers on the theory of option pricing .

Consider a writer of a European call option a stock, he is exposed to the risk of unlimited liability if the stock price rises acutely above the strike price. In an efficient market with no riskless arbitrage opportunity, and portfolio with a zero market risk must have an expected rate of return equal to the riskless interest rate. The Black-Scholes formulation establishes the equilibrium condition between the expected return on the option, the expected return on the stock and the riskless interest rate . Readers may be interested to read a more recent article ${ }^{[3]}$ (Black, 1989)on how Black and Scholes came up with the idea of a riskless hedging portfolio. The article considers the financial derivatives model with the credit risk. In this paper, though the value of corporation value model, the credit risk will be introduced to options pricing.

\section{For the Black-Scholes Option}

\subsection{Riskless hedging principle}

We illustrate how to use the riskless hedging principle to derive the governing partial differential equation for the price of a European call ${ }^{[4]}$. The derivation follows the approach used by Black and scholes in their seminal paper(1973). They made the following assumptions on the financial market:

(i) trading takes place continuously in time;

(ii) the riskless interest rate $r$ is known and constant over time;

(iii) the asset pays no dividend;

(iv) there are no transaction cists in buying or selling the asset or the option, and no taxes;

(v) the assets are perfectly divisible; 
(vi) there are no penalties to short selling and the full use of proceeds is permitted;

(vii) there are no riskless arbitrage opportunities.

The evolution of the asset price $\mathrm{S}$ at time $t$ is assumed to follow the Geometric Brownian motion

$$
d S=\mu S d t+\sigma S d Z
$$

Where $\mu$ is the expected rate of return and $\sigma$ is the volatility, and $d Z$ is the standard Wiener process.Both $\sigma$ and $\mu$ are assumed to be constant.Consider a portfolio which involves short selling of one unit of a European call option and long holding of $\triangle$ units of the underlying asset.The value of the portfolio $\Pi$ is given by

$$
\Pi=-c+\Delta S
$$

Where $\mathrm{c}=\mathrm{c}(\mathrm{S}, \mathrm{t})$ denotes the call price.The call price is a function of the asset price and time.Note that $\triangle \mathrm{S}$ here refers to $\triangle$ times $S$,not infinitesimal change in S.The use of this confusing symbol $\triangle$ will be justified later .Since both $\mathrm{c}$ and $\Pi$ are random variables,we apply the Ito Lemma to compute their stochastic differentials as follows:

$$
d c=\frac{\partial c}{\partial t} d t+\frac{\partial c}{\partial S} d S+\frac{1}{2} \frac{\partial^{2} c}{\partial S^{2}} \sigma^{2} S^{2} d t
$$

We obtain

$$
\frac{\partial C}{\partial t}+\frac{\partial C}{\partial S} r S+\frac{1}{2} \frac{\partial^{2} C}{\partial S^{2}} \sigma^{2} S^{2}=r C
$$

The above parabolic partial differential equation is called the Black-scholes equation. Note that the parameter $\mu$, which is the expected rate of return of the asset, does not appear in the equation .To complete the formulation of the option pricing model, we need to prescribe the auxiliary condition for the European call option .At expiry, the payoff of the European call is given by

$$
c=c(s, T)=\max \left(S_{T}-K, 0\right)
$$

\subsection{Risk neutrality $\operatorname{argument}^{[5]}$}

We would like to present an alternative approach of deriving the Black-Scholes equation for the option pricing model, by which the argument of risk neutrality can be explained in a more succinct manner (Cox and Ross $\left.{ }^{[6]}, 1976\right)$. Suppose we write the stochastic process followed by the option price as

$$
\frac{d c}{c}=\mu d t+\sigma d Z
$$

Where $\mu$ is the expected rate of return of c and $\sigma^{2}$ the corresponding variance of the rate of return . from Eq.(3).we have

$$
d c=\left(\frac{\partial c}{\partial t}+\mu S \frac{\partial c}{\partial S}+\frac{1}{2} \frac{\partial^{2} c}{\partial S^{2}} \sigma^{2} S^{2}\right) d t+\sigma S \frac{\partial c}{\partial S} d Z
$$

The above statement of risk neutrality can be represented mathematically as

$$
C=C(S, t)=e^{-r \tau} E\left[\max \left(S_{T}-K, 0\right)\right]
$$

The option pricing model takes the following form

$$
C=S N\left(d_{1}\right)-K e^{-r \tau} N\left(d_{2}\right)
$$

Where 


$$
\begin{aligned}
& d_{1}=\frac{\ln (S / K)+\left(r+\frac{\sigma^{2}}{2}\right) T}{\sigma \sqrt{T}}, \\
& d_{2}=d_{1}-\sigma \sqrt{\tau}=\frac{\ln (S / K)+\left(r-\frac{\sigma^{2}}{2}\right) \tau}{\sigma \sqrt{\tau}}, \\
& \tau=T-t, \sigma=\sqrt{\operatorname{var}(d S / S)} .
\end{aligned}
$$

The above call price formula can be interpreted using the language of probability. First, $N\left(d_{2}\right)$ is been as the probability of the call option being in-the-money at expiry and so $K N\left(d_{2}\right)$ can be interpreted as the risk neutral expectation of the payment made by the holder of the call option at expiry on exercising the option. Hence, the expectation of the call value at expiry is $S e^{r \tau} N\left(d_{1}\right)-K N\left(d_{2}\right)$,

which is then discounted by the factor $e^{-r \tau}$ in the risk neutral world to give the present value of the call price.

\section{3. option pricing with credit risk}

We would like to improve the original Black-Scholes formulation by relaxing some of the assumption in the model with credit risk. we consider the valuation of the chooser option, which has the feature that the holder can choose whether the option is a call or a put after a specified period of time from the starting date of the option contract.

A standard chooser option entitles the holder to risk, after a predetermined date $T_{c}$ in the future, whether the option is a standard European call or put with a common strike price $K$ for the remaining time to expiration $T-T_{c}$.If the current time iis taken to be zero, the payoff of the risk option on the date of choice $T_{c}$ is

$$
V\left(S_{T_{c}}, T_{c}\right)=\max \left(c\left(S_{T_{c}}, T-T_{c} ; K\right), P\left(S_{T_{c}}, T-T_{c} ; K\right)\right)
$$

Where $T-T_{c}$ is the time to expiry in both call and put price formulas above, and $S_{T_{c}}$ is the asset price at time $T_{c}$.We assume the underlying asset pays a continuous dividend yield at the rate $\mathrm{q}$. By the put-call parity relation, the above payoff function can be expressed as

$$
\begin{aligned}
V\left(S_{T_{c}}, T_{c}\right) & =\max \left(c, c+K e^{-r\left(T-T_{c}\right)}-S_{T_{c}} e^{-q\left(T-T_{c}\right)}\right) \\
& =c+e^{-q\left(T-T_{c}\right)} \max \left(0, K e^{-(r-q)\left(T-T_{c}\right)}-S_{T_{c}}\right)
\end{aligned}
$$

Hence, the risk option is equivalent to the combination of one call with exercise price $K$. Option at the current time is found to be

$$
\begin{gathered}
V(S, 0)=S e^{-q T} N(x)-K e^{-r T} N(x-\sigma \sqrt{T}) \\
+K e^{-r T} N\left(-y+\sigma \sqrt{T_{c}}\right)-S e^{-q T} N(-y)
\end{gathered}
$$

where $S$ is the current asset price and

$$
x=\frac{\ln \frac{S}{K}+\left(r-q+\frac{\sigma^{2}}{2}\right) T}{\sigma \sqrt{T}}, y=\frac{\ln \frac{S}{K}+(r-q) T+\frac{\sigma^{2}}{2} T_{c} .}{\sigma \sqrt{T_{c}}} .
$$

Risk aversion is the most important function of future market, and is also the basic reason of the developing of future market. As one of the most important species of financial futures, stock index future is important to avoid the systemic risk of stock markets. As the main method of risk aversion, Hedging is used to manage risk by hedgers, in order to lock profits. Finally, the results of empirical study show that the capital is closely related to the hedging ratio, and the hedging is very important to risk aversion, the hedging based on this model can improve the return of spot, so the model is appropriate. 


\section{Conclusion}

Options on stocks were first traded in organized exchange in 1973. Since then, there has been a dramatic growth in option market. Now, option business has made in the different exchange all over the word.The development of option trading aroused considerable interest among the academic community. Doctor Black and professor Scholes first gave an option price formula to calculate European Call option. Professor Merton and other scholars ${ }^{[7]}$ extend and complete it. First of all, the general valuation formula in given about the Europe option under the condition of incomplete market and default risk .Second, the use of Black-Scholes the risk-neutral option pricing for reference, application of martingale pricing and probability methods, we derive a number of special cases of the pricing formulation with credit risk. The pricing formula of European options with credit risk which assumed the debt and the risk-free rate $r$ is constant. Using the martingale and probability method to deduce the pricing formula of European option with credit risk.

\section{References}

[1] BLACK F, SCHOLES M. The pricing of options and corporate liabilities[J]. Journal of Political Economy, 1973, (81):637-659.

[2] MERTON R C.On the pricing of corporate debt: The risk structure of interest rate[J]. Journal of Finance, 1974, (29):449-470.

[3] AMMANN M. Credit risk valuation: methods, models and application[M]. Springer,2001:89-93.

[4] KLEIN P. Pricing Black-Scholes options with correlated cridit risk[J]. Journal of Banking and Finane,1996,(29)6:1211-1229.

[5] Myers S C. Determinants of corporate borrowing $[\mathrm{J}]$. Journal of Financial Economics, 1977,(5):147-175.

[6] Cox,Ross. J.C. The valuation of options for alternative stochastic processes. Journal of Financial Economics, 1976, 3:145-166.

[7] Trigeorgis L, Mason S P. Valuing managerial flexibility[J]. Midland Corporate Finance Journal, 1987,5(1):14-21. 